\title{
Presence of Carotid Plaque Is Associated with Rapid Renal Function Decline in Patients with Type 2 Diabetes Mellitus and Normal Renal Function (Diabetes Metab J 2019;43:840-53)
}

\author{
Min-Ji Kim, Jae-Han Jeon
}

Department of Internal Medicine, Kyungpook National University Chilgok Hospital, School of Medicine, Kyungpook National University, Daegu, Korea

Despite recent advances in the management of diabetes, increased cardiovascular diseases and microvascular diseases including chronic kidney diseases (CKDs) remain a challenge. $\mathrm{CKD}$ itself is considered as a strong predictor of cardiovascular disease [1], as previous data showed that older adults with CKD are 6-fold more likely to die from cardiovascular causes than developing end stage renal disease [2].

Diabetic kidney disease (DKD) is one of the strongest risk factor of atherosclerotic vascular disease in diabetes, and therefore it is included as an indication of primary prevention of cardiovascular diseases in patients with diabetes [3]. In patients with $\mathrm{DKD}$, the presence of plaque is significantly more prevalent compared with patient with CKD without diabetes, suggesting an additive role of hyperglycemia in the subclinical atherosclerosis [4]. In addition, another study also showed that diabetes is a major independent risk factor of subclinical atherosclerosis [5]. Although the clinical importance of subclinical atherosclerosis is well-established in DKD, no definite predictive markers for $\mathrm{DKD}$ are present so far.

In the recent article entitled 'Presence of carotid plaque is associated with rapid renal function decline in patients with type 2 diabetes mellitus and normal renal function, by Seo et al. [6], the authors suggest that subclinical atherosclerosis is correlated with subsequent rapid renal function decline independent of other clinical risk factors in patients with type 2 diabetes mellitus [6]. The authors have identified that the presence of carotid plaque (CP), as measured by common carotid intima-media thickness (CIMT) at baseline while renal function is normal, predicts rapid decline of renal function in succeeding 6 years of follow-up. It is noteworthy that this correlation was valid even after adjusting for multiple variables including age, duration of diabetes, and glycosylated hemoglobin (HbAlc) and etc. As the authors have claimed, this study is distinguished from other previous studies in that the study was prospective and exclusively enrolled patients with preserved renal function at the baseline $[7,8]$.

It should be noted that the rapid renal function decliners, who were defined as estimated glomerular filtration rate decline $>3.3 \%$ year, had longer duration of diabetes with higher $\mathrm{HbAlc}$ and were older at the baseline. Although statistical significance remained even after these confounders were adequately adjusted, it would have been more convincing if agematched or diabetes duration-matched non-decliners were enrolled and compared with patients with or without baseline CP, given that these two factors are of utmost importance in DKD progression.

In this prospective, multicenter observational cohort, follow-up CIMT indices as well as the degree of glycemic control
Corresponding author: Jae-Han Jeon (D) https://orcid.org/0000-0002-9217-968X Department of Internal Medicine, Kyungpook National University Chilgok Hospital, School of Medicine, Kyungpook National University, 807 Hoguk-ro, Buk-gu, Daegu 41404, Korea E-mail: jeonjh@knu.ac.kr
This is an Open Access article distributed under the terms of the Creative Commons Attribution Non-Commercial License (https://creativecommons.org/licenses/by-nc/4.0/) which permits unrestricted non-commercial use, distribution, and reproduction in any medium, provided the original work is properly cited. 
was not shown after baseline. Because it is generally believed that renal vascular supply is decreased in parallel to increased atheroma, combinatorial consideration of temporal changes of CIMT or HbA1c rather than cross-sectional baseline parameters would have better reflected deteriorated renal function.

In addition, although it is postulated that ischemic renal changes caused by atherosclerosis of the intrarenal arteries is the culprit of rapid renal deterioration, it should also be considered that DKD and atherosclerosis also share similar disease entity, i.e., inflammation. The pro-inflammatory milieu in CKD is thought to depend on both innate and adaptive immune system [9]. Accumulating preclinical evidences show increased cytokines in renal fibrosis or DKD [9-11]. Given that low-grade inflammation is also critically involved in the pathogenesis of atherosclerosis, it is also plausible that the patients with $\mathrm{CP}$ are more primed with inflammation, although no differences in surrogate marker of inflammation, such as high sensitivity $\mathrm{C}$ reactive protein, was noted between these two groups.

Taken together, the article by Seo et al. [6] clearly suggests that early and intensive monitoring of renal function is beneficial in patients with type 2 diabetes mellitus with comorbid $\mathrm{CPs}$ in terms of detection of rapid renal deterioration.

\section{CONFLICTS OF INTEREST}

No potential conflict of interest relevant to this article was reported.

\section{REFERENCES}

1. Go AS, Chertow GM, Fan D, McCulloch CE, Hsu CY. Chronic kidney disease and the risks of death, cardiovascular events, and hospitalization. N Engl J Med 2004;351:1296-305.

2. Dalrymple LS, Katz R, Kestenbaum B, Shlipak MG, Sarnak MJ, Stehman-Breen C, Seliger S, Siscovick D, Newman AB, Fried L. Chronic kidney disease and the risk of end-stage renal disease versus death. J Gen Intern Med 2011;26:379-85.

3. American Diabetes Association. 10. Cardiovascular disease and risk management: standards of medical care in diabetes-2020. Diabetes Care 2020;43(Suppl 1):S111-34.
4. Palanca A, Castelblanco E, Perpinan H, Betriu A, Soldevila B, Valdivielso JM, Bermudez M, Duran X, Fernandez E, PuigDomingo M, Groop PH, Alonso N, Mauricio D. Prevalence and progression of subclinical atherosclerosis in patients with chronic kidney disease and diabetes. Atherosclerosis 2018;276: 50-7.

5. Betriu A, Martinez-Alonso M, Arcidiacono MV, Cannata-Andia J, Pascual J, Valdivielso JM, Fernandez E; Investigators from the NEFRONA Study. Prevalence of subclinical atheromatosis and associated risk factors in chronic kidney disease: the NEFRONA study. Nephrol Dial Transplant 2014;29:1415-22.

6. Seo DH, Kim SH, Song JH, Hong S, Suh YJ, Ahn SH, Woo JT, Baik SH, Park Y, Lee KW, Kim YS, Nam M; KNDP Study Group. Presence of carotid plaque is associated with rapid renal function decline in patients with type 2 diabetes mellitus and normal renal function. Diabetes Metab J 2019;43:840-53.

7. Kaneko R, Sawada S, Tokita A, Honkura R, Tamura N, Kodama S, Izumi T, Takahashi K, Uno K, Imai J, Yamada T, Miyachi Y, Hasegawa H, Kanai H, Ishigaki Y, Katagiri H. Serum cystatin $\mathrm{C}$ level is associated with carotid arterial wall elasticity in subjects with type 2 diabetes mellitus: a potential marker of early-stage atherosclerosis. Diabetes Res Clin Pract 2018;139: 43-51.

8. Takenouchi A, Tsuboi A, Kurata M, Fukuo K, Kazumi T. Carotid intima-media thickness and visit-to-visit $\mathrm{HbAlc}$ variability predict progression of chronic kidney disease in type 2 diabetic patients with preserved kidney function. J Diabetes Res 2016;2016:3295747.

9. Pichler R, Afkarian M, Dieter BP, Tuttle KR. Immunity and inflammation in diabetic kidney disease: translating mechanisms to biomarkers and treatment targets. Am J Physiol Renal Physiol 2017;312:F716-31.

10. Pindjakova J, Hanley SA, Duffy MM, Sutton CE, Weidhofer GA, Miller MN, Nath KA, Mills KH, Ceredig R, Griffin MD. Interleukin-1 accounts for intrarenal Th17 cell activation during ureteral obstruction. Kidney Int 2012;81:379-90.

11. Tapmeier TT, Fearn A, Brown K, Chowdhury P, Sacks SH, Sheerin NS, Wong W. Pivotal role of CD4+ T cells in renal fibrosis following ureteric obstruction. Kidney Int 2010;78:35162. 